Xiong Wan-Ming, Di Yi-Bo, Lan Ying-Dong, Chen Jing, Nie Xu-Liang* and Huang Chang-Gan

\title{
Crystal structure of $1,1^{\prime}$-(ethane-1,2-diyl)bis (3-ethyl-1H-imidazol-3-ium)bis(hexafluorido phosphate), $\mathrm{C}_{12} \mathrm{H}_{20} \mathrm{~F}_{12} \mathrm{~N}_{4} \mathrm{P}_{2}$
}

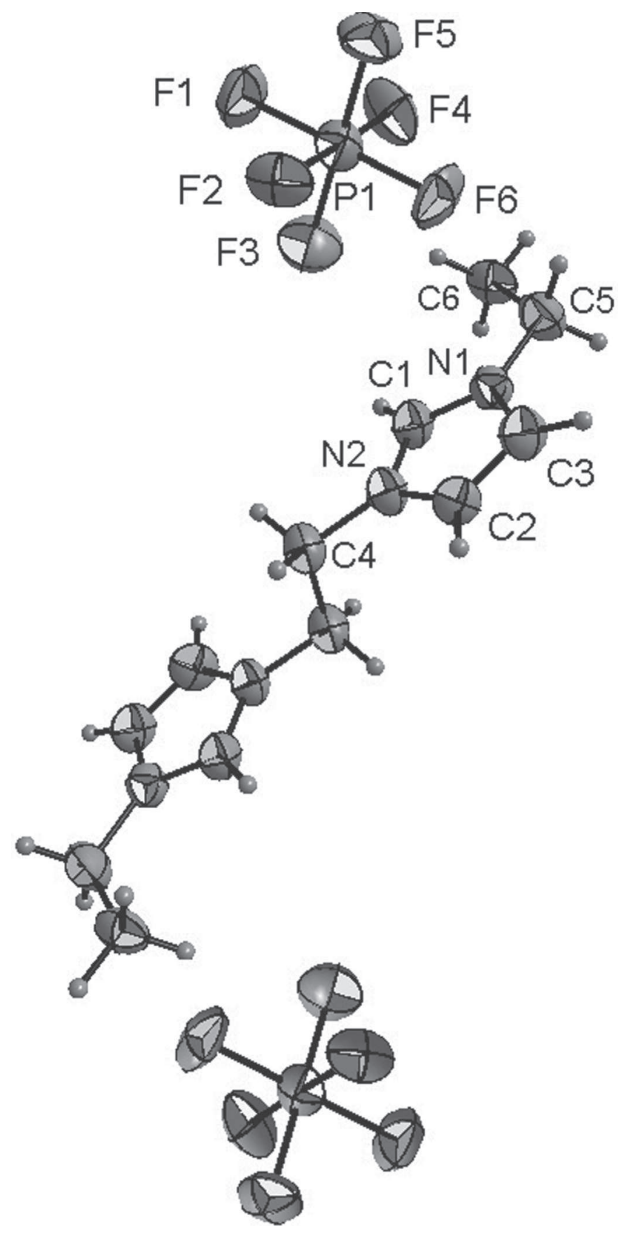

*Corresponding author: Nie Xu-Liang, Key Laboratory of Natural, Product Research and Development/College of Sciences, Jiangxi Agricultural University, Nanchang 330045, People's Republic of China, e-mail: niexuliang1981@163.com

Xiong Wan-Ming: Collaborative Innovation Center of Jiangxi Typical Trees Cultivation and Utilization/Institute of Functional Materials and Agricultural Applied Chemistry, Jiangxi Agricultural University, Nanchang 330045, People's Republic of China

Di Yi-Bo, Chen Jing and Huang Chang-Gan: College of Sciences, Jiangxi Agricultural University, Nanchang 330045, People's Republic of China

Lan Ying-Dong: Institute of Functional Materials and Agricultural Applied Chemistry/College of Sciences, Jiangxi Agricultural University, Nanchang 330045, People's Republic of China https://doi.org/10.1515/ncrs-2018-0178

Received May 18, 2018; accepted August 9, 2018; available online October 25, 2018

\author{
Abstract \\ $\mathrm{C}_{12} \mathrm{H}_{20} \mathrm{~F}_{12} \mathrm{~N}_{4} \mathrm{P}_{2}$, monoclinic, $P 2_{1} / c$ (no. 14), $a=7.012(2) \AA$, \\ $b=15.507(5) \AA, \quad c=10.398(2) \AA, \quad \beta=118.945(15)^{\circ}, \quad Z=2$, \\ $V=989.4(5) \AA^{3}, \quad R_{\mathrm{gt}}(F)=0.0526, \quad w R_{\mathrm{ref}}\left(F^{2}\right)=0.1537$, \\ $T=296(2) \mathrm{K}$.
}

CCDC no.: 1861132

The crystal structure is shown in the figure. Tables 1 and 2 contain details on crystal structure and measurement conditions and a list of the atoms including atomic coordinates and displacement parameters.

Table 1: Crystal collection and handling.

\begin{tabular}{ll}
\hline Crystal: & Block, colorless \\
Size: & $0.20 \times 0.16 \times 0.14 \mathrm{~mm}$ \\
Wavelength: & Mo $K \alpha$ radiation $(\lambda=0.71073 \AA)$ \\
$\mu:$ & $0.337 \mathrm{~mm}^{-1}$ \\
Diffractometer, scan mode: & Bruker APEX-II CCD, $\Phi$ and \\
& $\omega$-scans \\
$\theta_{\text {max }}$, completeness: & $25.5^{\circ},>99 \%$ \\
$N(h k l)_{\text {measured }}, N\left(h k l l_{\text {unique }}, R_{\text {int }}:\right.$ & $7271,1855,0.0432$ \\
Criterion for $I_{\text {obs }}, N(h k l)_{\text {gt }}:$ & $I_{\text {obs }}>2 \sigma\left(I_{\text {obs }}\right), 1304$ \\
$N(\text { param })_{\text {refined }}:$ & 137 \\
Programs: & Bruker programs [1], SHELX [2]
\end{tabular}

\section{Source of materials}

1-Ethylimidazole ( $9.61 \mathrm{~g}, 0.1 \mathrm{~mol})$ was dissolved in methylbenzene ( $20 \mathrm{~mL}$ ), 1,2-dibromoethane ( $9.393 \mathrm{~g}, 0.05 \mathrm{~mol}$ ) was quickly added under stirring. The mixture was first reacted at $60{ }^{\circ} \mathrm{C}$ for $10 \mathrm{~min}$, and then heated to $110{ }^{\circ} \mathrm{C}$ for $8 \mathrm{~h}$. After the reaction completed (monitored by TLC), a white solid was produced on slow cooling. The resulting suspension was filtered, crushed and washed with ethylacetate and diethyl ether 3 times respectively. The white powder intermediate (C2M$\mathrm{Br})$ dryed in vacuo (16.72 g, yield 88\%). Then the intermediate (C2M-Br) (3.80 g, $0.01 \mathrm{~mol})$, potassium hexafluorophosphate (5.38 g, $0.026 \mathrm{~mol})$ was dissolved in water $(40 \mathrm{~mL})$. The 
Table 2: Fractional atomic coordinates and isotropic or equivalent isotropic displacement parameters $\left(\AA^{2}\right)$.

\begin{tabular}{lrrrr}
\hline Atom & $\boldsymbol{x}$ & $\boldsymbol{y}$ & $\boldsymbol{z}$ & $\boldsymbol{U}_{\text {iso }}{ }^{*} \boldsymbol{U}_{\text {eq }}$ \\
\hline P1 & $0.28340(15)$ & $0.38522(5)$ & $0.23936(9)$ & $0.0454(3)$ \\
F1 & $0.1900(4)$ & $0.45033(15)$ & $0.1072(3)$ & $0.0875(8)$ \\
F2 & $0.0508(5)$ & $0.37866(16)$ & $0.2265(4)$ & $0.1022(10)$ \\
F3 & $0.2283(4)$ & $0.30818(14)$ & $0.1285(2)$ & $0.0802(7)$ \\
F4 & $0.5143(4)$ & $0.3942(2)$ & $0.2504(3)$ & $0.0996(9)$ \\
F5 & $0.3377(5)$ & $0.46287(15)$ & $0.3512(3)$ & $0.0870(8)$ \\
F6 & $0.3755(6)$ & $0.32007(17)$ & $0.3715(3)$ & $0.1119(11)$ \\
N1 & $0.4895(4)$ & $0.12781(15)$ & $0.2988(3)$ & $0.0433(6)$ \\
N2 & $0.1745(4)$ & $0.07467(16)$ & $0.1524(3)$ & $0.0427(6)$ \\
C1 & $0.3488(5)$ & $0.11304(19)$ & $0.1608(3)$ & $0.0437(7)$ \\
H1 & 0.3684 & 0.1273 & 0.0811 & 0.052 \\
C2 & $0.2090(6)$ & $0.0638(2)$ & $0.2936(4)$ & $0.0513(8)$ \\
H2 & 0.1145 & 0.0380 & 0.3212 & 0.062 \\
C3 & $0.4035(6)$ & $0.0973(2)$ & $0.3827(4)$ & $0.0530(9)$ \\
H3 & 0.4696 & 0.0996 & 0.4847 & 0.064 \\
C4 & $-0.0145(5)$ & $0.0460(2)$ & $0.0173(3)$ & $0.0464(8)$ \\
H4A & -0.0340 & 0.0831 & -0.0633 & 0.056 \\
H4B & -0.1441 & 0.0502 & 0.0279 & 0.056 \\
C5 & $0.7064(6)$ & $0.1674(2)$ & $0.3568(4)$ & $0.0598(10)$ \\
H5A & 0.8160 & 0.1251 & 0.4155 & 0.072 \\
H5B & 0.7177 & 0.2148 & 0.4211 & 0.072 \\
C6 & $0.7543(6)$ & $0.2004(3)$ & $0.2416(5)$ & $0.0733(12)$ \\
H6A & 0.7512 & 0.1535 & 0.1803 & 0.110 \\
H6B & 0.8961 & 0.2266 & 0.2870 & 0.110 \\
H6C & 0.6467 & 0.2424 & 0.1827 & 0.110 \\
\hline & & & &
\end{tabular}

mixture stirred well for $12 \mathrm{~h}$ at $95{ }^{\circ} \mathrm{C}$ and then cooled slowly to give the crystals.

\section{Experimental details}

All $\mathrm{H}$ atoms were included in calculated positions and refined as riding atoms, with $\mathrm{C}-\mathrm{H}=0.90-0.97 \AA$ with $U_{\text {iso }}(\mathrm{H})=1.5$ $U_{\text {eq }}(\mathrm{C})$ for methyl $\mathrm{H}$ atoms and $1.2 U_{\text {eq }}(\mathrm{C})$ for all other $\mathrm{H}$ atoms.

\section{Comment}

Ionic liquid, as a new type of environmentally friendly solvent and liquid acid base catalyst, owing to the advantages of adjustable structure, high catalytic efficiency, mild conditions, and can be recycled, etc, has been widely used in biomass energy. many fields of research. Because of the unique physical and chemical properties of ionic liquids, they have potential advantages of biodiesel preparation [3-5]. In recent years, various functional ionic liquids have been synthesised, and have been used to prepare biodiesel highly efficiently and environmental friendly $[6,7]$. It was found that dinuclear alkaline ionic iquid bis-(3-methyl-1-imidazolium-) ethlyene dihydroxide ([MC2]OH) shows excellent catalytic efficiency, the highest conversion rate of cotton seed oil was up to $98.5 \%$ [8]. Our group is still focused on the preparation of biodiesel catalyzed by ionic liquid $[9,10]$ and already reported some structures directly reacted to the title compound [11-13]. In order to find the ionic liquid catalyst with better catalytic efficiency, we were engaged in the synthesis of new ionic liquid catalysts with imidazole.

Bond lengths and angles within the imidazloe ring are very similar to those given in the literature for diimidazloe ionic liquid [11-14]. The asymmetric unit of the title structure consists of one half of $C 2 M^{2+}$ cation (1,1'-(ethane-1,2-diyl) bis(3-ethyl- $1 H$-imidazol-3-ium)) and one $\left[\mathrm{PF}_{6}\right]^{-}$anion ( $c f$. the figure). Two cationic 1-ethylimidazolium rings were bound to the both sides of ethyl group. The two imidazole rings are crystallographically dependant, planar and parallel to each other. The torsion angle of C4-N2-C2-C3 and C4'-C4-N2-C1 is $178.2^{\circ}$ and $86.4^{\circ}$ respectively.

Acknowledgements: X-ray data were collected at Instrumental Analysis Center Nanchang Hangkong University, Nanchang 330063. This work was supported by the National Natural Science Foundation of China (Nos. 31760193, 31760068) and the Research Foundation of Educational Department of Jiangxi Province [GJJ160382, 160408].

\section{References}

1. Bruker. APEX2, SAINT and SADABS. Brucker AXS Inc., Madison, WI, USA (2009).

2. Sheldrick, G. M.: A short history of SHELX. Acta Crystallogr. A64 (2008) 112-122.

3. Zhen, B.; Jiao, Q. Z.; Wu, Q.; Li, H. S.: Catalytic performance of acidic ionic liquid-functionalized silica in biodiesel production. J. Energy Chem. 23 (2014) 97-104.

4. Rafiee, E.; Eavani, S.: A new organic-inorganic hybrid ionic liquid polyoxometalate for biodiesel production. J. Mol. Liq. 199 (2014) 96-101.

5. Fan, M. M.; Zhou, J. J.; Han, Q. J.; Zhang, P. B.: Effect of various functional groups on biodiesel synthesis from soybean oils by acidic ionic liquids. Chin. Chem. Lett. 23 (2012) 1107-1110.

6. Han, X. X.; He, Y. F.; Hung, C. T.; Liu, L. L.; Huang, S. J.; Liu, S. B.: Efficient and reusable polyoxometalate-based sulfonated ionic liquid catalysts for palmitic acid esterification to biodiesel. Chem. Eng. Sci. 104 (2013) 64-72.

7. Li, Y.; Hu, S. G.; Cheng, J. H.; Lou, W. Y.: Acidic ionic liquid catalyzed esterification of oleic acid for biodiesel synthesis. Chinese J. Catal. 35 (2014) 396-406.

8. Liang, J. H.; Ren, X. Q.; Wang, J. T.; Jinag, M.; Li, Z. J.: Preparation of biodiesel by transesterification from cotton seed oil using the basic dication ionic liquids as catalysts. J. Fuel Chem. Tech. 38 (2010) 275-280.

9. Xiong, W. M.; Zhu, M. Z.; Deng, L.; Fu, Y.; Guo, Q. X.: Esterification of organic acid in bio-oil using acidic ionic liquid catalysts. Energy Fuels 23 (2009) 2278-2283.

10. Kong, J. H.; Lan, Y. D.; Chen, J.; Huang, C. G.; Xiong, W. M.: Preparation and component analysis of biodiesel catalyzed by functionalized dication ionic liquid. Acta Agric. Univ. Jiangxiensis. 38 (2016) 386-390. 
11. Xiong, W. M.; Chen, J.; Peng, D. Y.; Nie, X. L.; Huang, C. G.: Crystal structure of 1,1'-butanebis(3-methyl-1H-imidazol-3ium), bis(hexafluorophosphate), $\mathrm{C}_{12} \mathrm{H}_{20} \mathrm{~F}_{12} \mathrm{~N}_{4} \mathrm{P}_{2}$. Z. Kristallogr. NCS 232 (2017) 1007-1008.

12. Nie, X. L.; Kong, J. H.; Chen, J.; Chen, J. Z.; Xiong, W. M.: Crystal structure of 1,1'-(hexane-1,6-diyl)bis(3-methyl-1H-imidazol-3ium)bis(hexafluoro phosphate), $\mathrm{C}_{9} \mathrm{H}_{14} \mathrm{~F}_{12} \mathrm{~N}_{4} \mathrm{P}_{2}$. Z. Kristallogr. NCS 232 (2017) 73-74.
13. Xiong, W. M.; Zhou, L.; Lv, S. M.; Nie, X. L.; Chen, J.; Huang, C. G.: Crystal structure of $1,1^{\prime}$-(pentane-1,5-diyl)bis(3-methyl-1Himidazol-3-ium), bis(hexafluorophosphate), $\mathrm{C}_{9} \mathrm{H}_{14} \mathrm{~F}_{12} \mathrm{~N}_{4} \mathrm{P}_{2}$. Z. Kristallogr. NCS 233 (2018) 473-474.

14. Li, M.; Niu, Z. B.; Schoonover, D. V.; Slebodnick, C.; Gibson, H. W.: 1,2-Bis(N-(N'-alkylimidazolium))ethane salts as new guests for crown ethers and cryptands. Tetrahedron 66 (2010) 7077-7082. 